\title{
Cardiac Rescue of an Infant With Fulminant Myocarditis Using Extracorporeal Membrane Oxygenation
}

\author{
Noriko Nagai, M.D., Ryosuke Ogura, M.D., Akira Seki, M.D* \\ Makoto Kajiyama, M.D., Hiroshi Masumoto, M.D.* \\ and Michio Sasaki, M.D*
}

\begin{abstract}
A 7-month-old boy presented with fulminant myocarditis. He was in cardiac shock and cardiac dysfunction progressed despite aggressive support. Extracorporeal membrane oxygenation (ECMO) was applied for 8 days and he recovered with mild dilated cardiomyopathy.
\end{abstract}

(Jpn Circ J 1996; 60: 699-702)

$\mathbf{T}^{\mathrm{T}}$

HE incidence of fulminant myocarditis is reportedly about $20-30 \%$ in myocarditis, and approximately one-third of these patients die within the first month! However, as many as one-third can recover if they can survive the critical period!-5 Although mechanical support such as intra-aortic balloon counterpulsation is common in adults, pediatric applications are limited. In the case reported here, we used extracorporeal membrane oxygenation (ECMO) for an infant in cardiogenic shock. ECMO is very useful in fulminant carditis for supporting the circulation during the critical phase.

\section{CASE REPORT}

A previously healthy 7 -month-old, $7.5 \mathrm{~kg}$ boy was brought to the emergency room of our hospital with a 3 days history of rhinorrhea, cough, fever, and progressive tachypnea and lethargy. On admission, he looked ill with a pale complexion. He was grunting with 60 breaths/min and a heart rate of 130 beats/min. His blood pressure could

Key words:

Fulminant myocarditis

Extracorporeal membrane oxygenation (ECMO)

Infant

Cardiac rescue not be measured because of a very weak pulse. There were no heart murmurs, but a galloping rhythm was observed. The liver was palpable $8 \mathrm{~cm}$ below the right costal margin.

Chest radiograph showed cardiomegaly and electrocardiogram (ECG) showed a wide $\mathrm{QRS}$ with a $\mathrm{QS}$ pattern in $\mathrm{I}, \mathrm{a} V_{\mathrm{L}}$, a very low $R$ wave in $V_{4}$ to $V_{6}$, and ST-segment elevation in $V_{1}$ to $V_{5}$ and depression in II, III, and aVF (Fig 1). Echocardiogram showed severe myocardial dysfunction, with a left ventricular ejection fraction (LVEF) of $10 \%$, a left end-diastolic diameter (LVDd) of $54 \mathrm{~mm}$, and mild to moderate mitral regurgitation. The serum creatine kinase level was elevated $(217 \mathrm{IU} / \mathrm{L})$ and had increased further the next day (681 IU/L). CRP was negative. Therefore, we gave a diagnosis of viral myocarditis.

Soon after admission, he was intubated and maintained on mechanical ventilation. $\mathrm{He}$ initially received an intravenous infusion of dopamine $(5-7 \mu \mathrm{g} / \mathrm{kg}$ per min) to support his blood pressure. Human $\gamma$-globulin (IVIG) was administered $(300 \mathrm{mg} / \mathrm{kg}$ per day for 6 days) for immunological treatment.

Ventricular tachycardia occurred twice, but stopped spontaneously. The next day,

(Received July 17, 1995; accepted November 24, 1995)

Department of Pediatrics, * Department of Cardiovascular Surgery, Okazaki Municipal Hospital, Okazaki, Japan

Mailing address: Noriko Nagai, M.D., Department of Pediatrics, Okazaki Municipal Hospital 2-2 Wakamiya-Cho, Okazaki, Aichi 444, Japan 


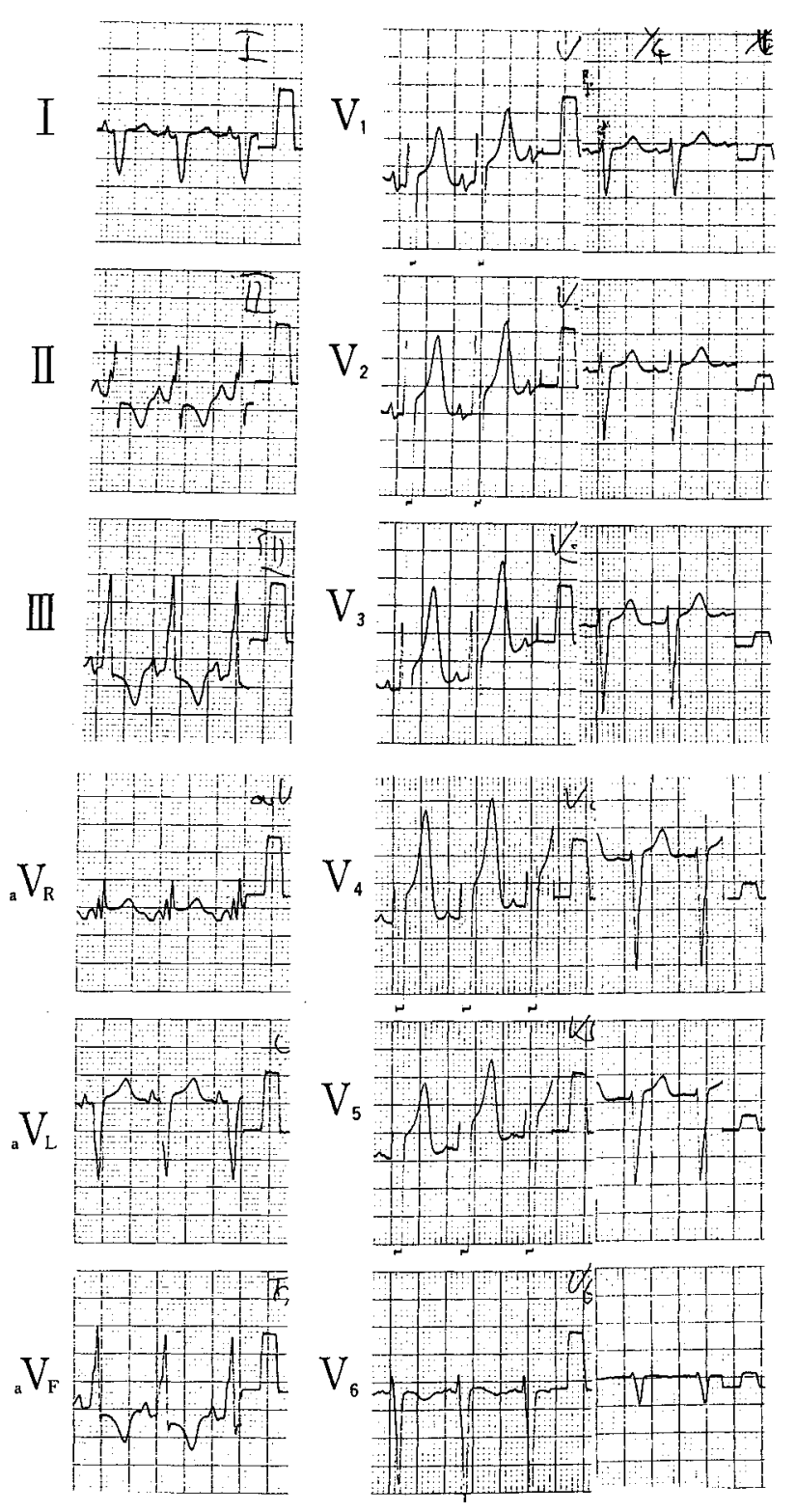

Fig 1. ECG on admission.

his condition had deteriorated. Therefore, we prepared ECMO. Twenty six hours after admission, he had a sudden episode of bradycardia $(50-60$ beats $/ \mathrm{min})$ and hypotension $(<20 \mathrm{mmHg})$. He was resuscitated by external cardiac massage, intravenous bicarbonate, high-dose isoproterenol, epinephrine and norepinephrine. He was cannulated for ECMO using the right carotid artery and the internal jugular vein. ECMO flows were maintained at approximately $100 \mathrm{ml} / \mathrm{kg}$ per $\mathrm{min}$, but were changed to a minimum of $60 \mathrm{ml} / \mathrm{kg}$ per min because of mild aortic and mitral regurgitation and left ventricular dilatation. Inotropes were tapered but continued at

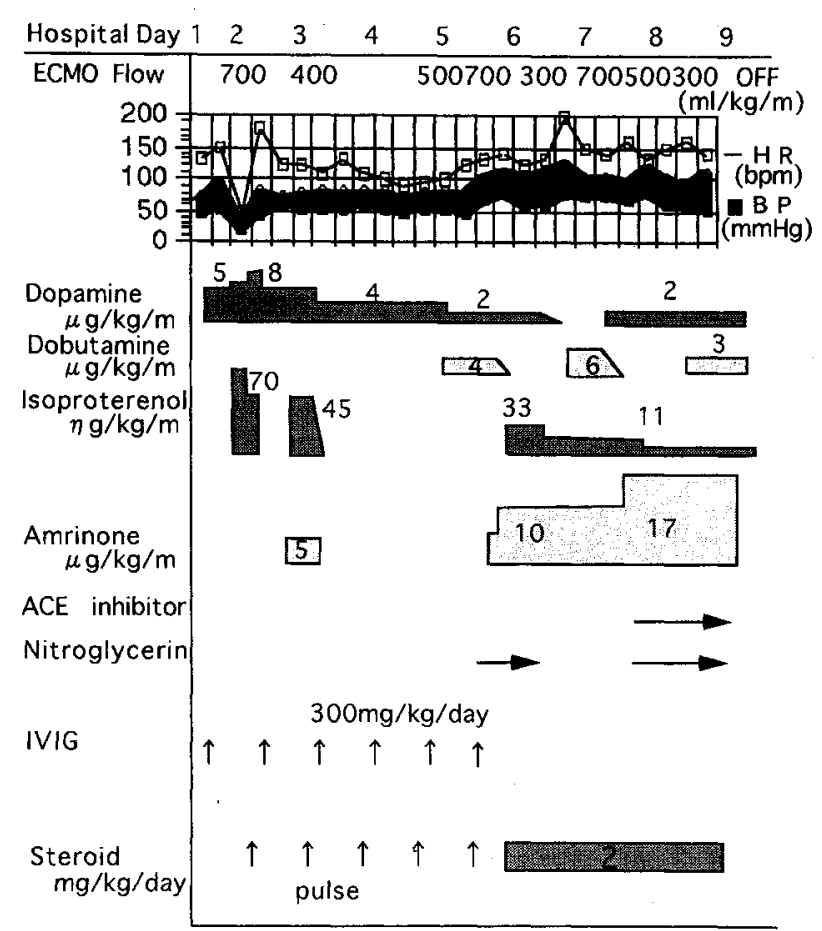

Fig 2. Changes in hemodynamic status and treatments during extracorporeal membrane oxygenation (ECMO).

HR: heart rate, BP: blood pressure, ECMO Flow: flow of extracorporeal membrane oxygenation (ECMO), IVIG: intravenous human $\gamma$-globulin.

low doses because of peripheral circulatory failure, along with angiotensin converting enzyme (ACE) inhibitor, diuretics and amrinone. Steroid pulse therapy was also applied. Fig 2 shows the course of treatment during ECMO. On day 9, when ECMO was discontinued, echocardiographic LVEF was $35 \%$ and EVDd was $46 \mathrm{~mm}$. Mechanical ventilation support was stopped on day 16 and all intravenous inotropes were discontinued by day 29 .

After 8 weeks, a right ventricular endomyocardial biopsy was performed. There was some fibrosis and slight inflammatory infiltrate, and he was diagnosed as healing myocarditis (Fig 3).

He was discharged on day 69. After 4 months, left ventricular function had somewhat recovered (LVEF; $55 \%$ and LVDd; $32 \mathrm{~mm}$ ). His neurological development has been normal.

\section{DISCUSSION}

Acute viral myocarditis is initiated by 


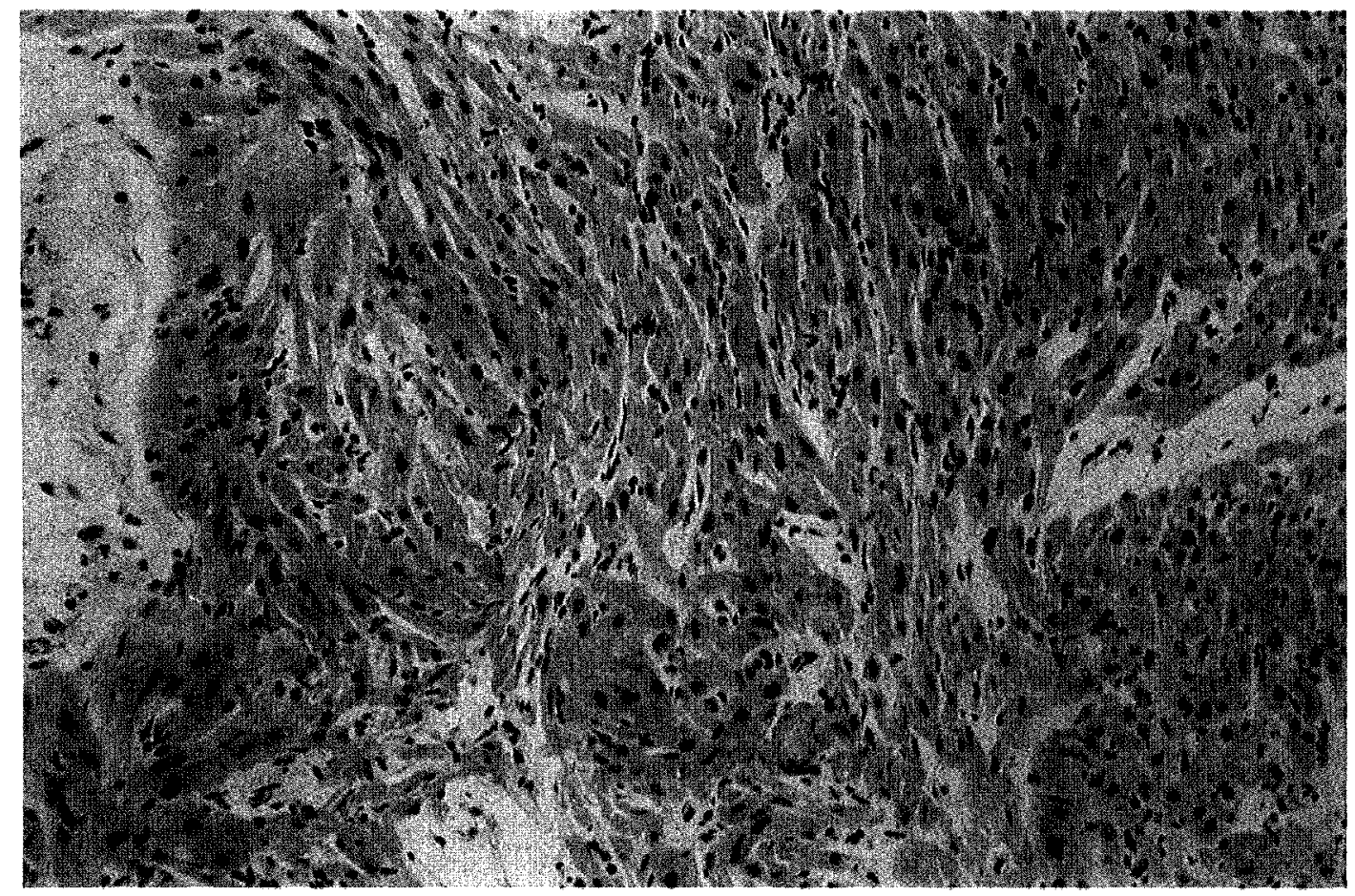

Fig 3. Histopathology of right ventricular biopsy specimen taken on day 61 (hematoxylin $\operatorname{eosin}, \times 250)$

viral infection, 1,6 and subsequent myocardial damage may be mediated by autoimmune mechanisms in addition to direct viral infection?-10 Fulminant myocarditis appears to be the result of a high level of virus and diffuse lymphocytic infiltrate! Approximately a third of these patients will die or be transplanted, another third will develop dilated cardiomyopathy, and a third will recover completely! However, since cardiac dysfunction is affected by some cytokines, 11 the rate of recovery may be higher with life support during the critical period. The patient in this report would most likely have died without cardiopulmonary support by ECMO, despite conventional treatments.

ECMO is generally used to treat neonates with respiratory failure ${ }^{12}$ or cardiac dysfunction after cardiac surgery? In adults, there have been some reports of percutaneous cardiopulmonary support (PCPS) for acute myocarditis.,5 The major complications of PCPS and ECMO are bleeding and infection. Our case had no complications, but did develop left ventricular distention when ECMO flow became afterload. To reduce afterload, low-dose inotropes, vasodilator, and ACE inhibitor were administered and ECMO flow was reduced for the first 3 days.
The efficacy of immunosuppression therapy for acute myocarditis remains controversial1,7-10 Steroid may increase virus numbers and may enhance fulminant myocarditis during the early phase ( 3 to 5 days after virus injection)! However, Drucker et al used steroid after IVIG therapy and their cases showed complete recovery? We used steroid on the fifth day after the fever began after IVIG therapy.

Heart transplantation is the last option in severe cardiac dysfunction, 1,13 but is currently unavailable in Japan. In the present case, ECMO was useful for rescuing fulminant myocarditis, and may change the prognosis of this disease.

\section{Acknowledgments}

We thank Dr. Toshiro Nishikawa, Department of Pathology, Tokyo Women's Medical College, and Dr. Atsuko Nakagawa, Department of Pathology, Nagoya University Hospital, for interpreting the biopsy specimens.

\section{REFERENCES}

1. Lewis $\mathrm{AB}$ : Myocarditis. In: Emmanouilides GC, et al editors. Moss and Adams' heart disease in infants, children, and adolescents. Baltimore: Williams and Wilkins, 1995; $1381-1390$

2. Grundl PD, Miller SA, Nido PJD, Beerman 
LB, Fuhrman BP: Successful treatment of acute myocarditis using extracorporeal membrane oxygenation. Crit Care Med 1993; 21: 302-304

3. Dalton HJ, Siewers R, Fuhrman BP, et al: Extracorporeal membrane oxygenation for cardiac rescue in children with severe myocardial dysfunction. Crit Care Med 1993; 21: 1020-1028

4. Morishima I, Sassa H, Sone T, Tsuboi H, Kondo J, Koyama $\mathrm{T}$ : A case of fulminant myocarditis rescued by long-term percutaneous cardiopulmonary support. Jpn Circ J 1994; 58: 433 - 438

5. Tsuboi H, Sone T, Sassa H, et al: Rescue of a patient with fulminant myocarditis by percutaneous extracorporeal bypass. Jpn $J$ Med 1990; 29: $519-522$

6. Martin AB, Webber S, Fricker FJ, et al: Acute myocarditis: rapid diagnosis by PCR in children. Circulation 1994; 90: $330-339$

7. Lange LG, Schtriner GF: Immune mechanisms of cardiac disease. $N$ Engl J Med 1994; 330: $1129-1135$

8. Balaji S, Wiles HB, Sens MA, Gillette PC:
Immunosuppressive treatment for myocarditis and borderline myocarditis in children with ventricular ectopic rhythm. Br Heart $J$ 1994; 72: 354-359

9. Drucker NA, Colan SD, Lewis $\mathrm{AB}$, et al: $\gamma$ Globulin treatment of acute myocarditis in the pediatric population. Circulation 1994; 89: $252-257$

10. Davies MJ: How can myocarditis be diagnosed and should it be treated? Br Heart $J$ 1992; 68: 346-347

11. Matsumori A, Yamada T, Suzuki H, Matoba Y, Sasayama S: Increased circulating cytokines in patients with myocarditis and cardiomyopathy. $\mathrm{Br}$ Heart $J$ 1994; 72: $561-566$

12. Bartlett RH, Roloff DW, Cornell RG, Andrews AF, Dillon PW, Zwischenberger JB: Extracorporeal circulation in neonatal respiratory failure: a prospective randomized study. Pediatrics 1985; 76: 479-487

13. Burch M, Siddiqi SA, Celermajer DS, Scott C, Bull C, Deanfield JE: Dilated cardiomyopathy in children: determinants of outcome. $\mathrm{Br}$ Heart $J$ 1994; 72: $246-250$ 